\title{
Serious Games for Post-Stroke Rehabilitation Using Microsoft Kinect
}

\author{
Azrulhizam Shapi'i, Haslina Arshad, Mohd Syazwan Baharuddin, Hafiz Mohd Sarim \\ Faculty of Information Science \& Technology, Universiti Kebangsaan Malaysia, 43600 Bangi,Malaysia \\ E-mail:azrulhizam@ukm.edu.my,haslinarshad@ukm.edu.my,syazwan@ukm.edu.my,hms@ukm.edu.my
}

\begin{abstract}
Traditional rehabilitation is a tedious task which typically reduces the patient's motivation to perform rehabilitation exercises. Patients therefore need a program that can entice them to do rehabilitation exercises continuously. The proposed game includes two different types of game and three different types of movement for interacting with the game. The game was designed and developed based on the elements of a rehabilitation game and the types of movement in rehabilitation exercises. The interface was developed with the aim of increasing the motivation of players, and the design was based on an analysis of the technology constraints faced by post-stroke patients. Since these patients experience physical limitations, Microsoft Kinect was used for interaction in this game. Using Kinect, the patient is not bound by the controller to interact with the game. Therefore, rehabilitation exercise games that support multi-player will provide a higher motivation than the single-player. Since most stroke patients suffer from cognitive impairment, cognitive challenge levels are also the key factors in the design of the game so that it does not become an obstacle for the recovery process. This research develops a prototype of a rehabilitation exercise game that contains aspects of the social context, the type of movement and cognitive challenges. It also provides usability in game design, according to a post-stroke stage so that they can perform recovery activities based on their ability. In addition, this study highlights technology and rehabilitation exercise games in Malaysia.The game also adds a social context that gives patients the opportunity to have a friend to play either by competition or cooperation. The contribution of this research is to measure the effectiveness of Microsoft's Kinect game console and this game can help in recovery the post-stroke patients do additional exercises at home without the supervision of therapist.
\end{abstract}

Keywords - post-stroke game; exercise game; kinect; rehabilitation game; natural user interface.

\section{INTRODUCTION}

Strokes are a primary reason for disability in adults over a long period. A stroke occurs when blood flow to the brain is disrupted due to a blood clot blocking an artery or rupture of blood vessels. This causes brain cells to die and the brain function to be impaired. In general, the consequences of a stroke can lead to limitations on movement, including paralysis, abnormal movement control, loss of coordination, limb position abnormalities, loss of memory and so on.

Physical therapy is a primary treatment for motor disorder, and involves tensing, stretching and strengthening the muscles. This exercise has the clear objective of maintaining and improving movement, preventing defects, enhancing muscle strength and improving coordination of movements, in order to maximize the patient's comfort and mobility. The emphasis on specific task training is important, since research has shown that stimulating practical movements while achieving goals produces better success than through repetition alone [1]. However, studies conducted by researchers have shown that many post-stroke patients do not exercise as prescribed at home. Post-stroke patients discharged from hospital have limited therapy sessions, for example once a week, and the amount of exercise in therapy sessions is insufficient [1]. To solve the problem, therapists always prescribe rehabilitation exercises to be carried out at home; however, only $31 \%$ of post-stroke patients do these additional recovery exercises as prescribed [2]. Post-stroke patients who do not do these additional recovery exercises recover more slowly, and this makes them less motivated [3].

In recent years, computer games and simulations have become recognized as motivational tools in the process of recovery. However, a serious game needs to fulfil certain requirements in order to be used in the rehabilitation process. There is ample evidence to show that virtual reality has a positive effect in recovering from a stroke. A variety of different paradigms are used including learning by imitating a movement, using vibration feedback, a repeated strong workout, mental training and so on. Virtual reality technology is expected to be important in the future development of rehabilitation programs [4]. Motion-based video games allow players to interact with a system through body movement and voice, and use motion capture technology for interaction. 
A rehabilitation system can be created using a Kinect sensor as a console to interact with the game; this is intended to improve exercises performed by patients using a natural interface that allows the body to interact with free movement [5]. Kinect is software that enables the capture, tracking and interpretation of body movements, gestures and voice commands. In other words, when using the Kinect, players do not need to use a keyboard, mouse or video game controller, which would burden patients and limit the patient's movement [6].

Factors such as social support from family members, the relationship between patient and therapist in a therapy session, and changes in the responsibilities of family members support the process of rehabilitation and the patient's way of life, both in the short and long term. Music is important in motivating the patients to do the rehabilitation process continuously, and can increase the recovery rate of stroke patients [7].

The specific aims of this project were to: (1) identify the requirements of conventional rehabilitation exercises for post-stroke patients; (2) design rehabilitation games that match conventional rehabilitation exercises; and (3) to test the usability and effectiveness of a rehabilitation game.

The primary purpose of purchasing serious games is not entertainment. The use of serious games for rehabilitation is still in the early stages, but in recent years this has become an active area of research. These games have been widely adopted to assist in therapy for strokes, brain traumas, single nerve injuries, and so on. There are also a range of therapies such as upper limb exercises, rehabilitation and restoration of balance in the parts of a particular limb. "Serious games for health" or "games for health" form a promising domain of research for the health and ICT sector, and there is therefore a great deal of research on this topic. There are various health-related applications which vary with the different types of users, such as doctors, students, patients, researchers, the public and others. Games for health can be used in various applications such as diagnostics, training, rehabilitation and fitness.

Many studies have been conducted to identify the advantages of using serious games in recovery and therapy. Since game technology is cheap, readily available, and can be fun and entertaining for various age groups, when combined with conventional health care it can produce a tool that can attract and encourage patients to use it effectively as a serious game for rehabilitation. Serious games must meet certain requirements for use in recovery [8]. The most critical needs, which are not catered for in commercial games, can involve changes to the resolution or configuration of the system or the game, for example the speed of the game and the calibration of the input. Thus, various aspects need to be emphasized, including an appropriate level of challenge, motion analysis, motion capture and others.

\section{MATERIAL AND METHOD}

\section{A. Game Element}

Many researchers agree that when the process of rehabilitation involves video game elements, the patient will be more motivated [5][9][10][11]. In order to identify the elements of a game that can be used in the development of prototypes for the rehabilitation of post-stroke patients, an analysis has been carried out of a literature review of these game elements.

TABLE I

GAME ELEMENT ANALYSIS

\begin{tabular}{|c|c|c|c|}
\hline No & Researcher & Game Element & Note \\
\hline 1 & $\begin{array}{l}\text { Gazihan and } \\
\text { Caitlin [1] }\end{array}$ & $\begin{array}{ll}\text { i. } & \text { Objective } \\
\text { ii. } & \text { Challenge } \\
\text { iii. } & \text { Feedback } \\
\text { iv. } & \text { Reward }\end{array}$ & $\begin{array}{l}\text { Elements of } \\
\text { rehabilitation } \\
\text { games that can } \\
\text { motivate a } \\
\text { patient }\end{array}$ \\
\hline 2 & $\begin{array}{l}\text { Gazihan et } \\
\text { al. [19] }\end{array}$ & \begin{tabular}{|ll} 
i. & Audio-visual \\
& aspects \\
ii. & Correct level \\
iii. & Non-player \\
& character (NPC) \\
& and story \\
\end{tabular} & $\begin{array}{l}\text { Elements of } \\
\text { rehabilitation } \\
\text { games that can } \\
\text { motivate a } \\
\text { patient }\end{array}$ \\
\hline 3 & $\begin{array}{l}\text { Timmermas } \\
\text { et al. [20] }\end{array}$ & \begin{tabular}{|ll} 
i. & Correct level \\
ii. & Meaningful tasks \\
iii. & Feedback \\
iv. & Correct motion \\
& range \\
v. & Focus can be \\
& shifted \\
vi. & Movement done \\
& intentionally \\
vii. & Quantitative \\
& measurement \\
\end{tabular} & $\begin{array}{l}\text { The effective } \\
\text { basic } \\
\text { components of } \\
\text { rehabilitation }\end{array}$ \\
\hline 4 & $\begin{array}{l}\text { Aung et al. } \\
{[21]}\end{array}$ & 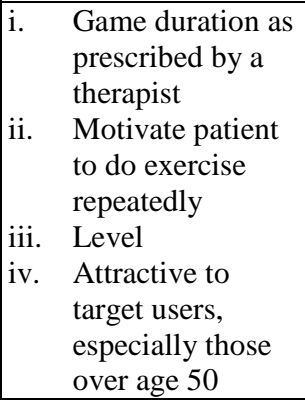 & $\begin{array}{l}\text { Six video } \\
\text { game designs } \\
\text { that can be } \\
\text { used } \\
\text { effectively for } \\
\text { constraint- } \\
\text { induced } \\
\text { movement } \\
\text { therapy }\end{array}$ \\
\hline 5 & $\begin{array}{l}\text { Daniel et al. } \\
{[22]}\end{array}$ & $\begin{array}{ll}\text { i. } & \text { Clear objective } \\
\text { ii. } & \begin{array}{l}\text { Reward and } \\
\text { achievement }\end{array} \\
\text { iii. } & \begin{array}{l}\text { Level and } \\
\text { challenge }\end{array} \\
\text { iv. } & \text { Social } \\
\text { environment }\end{array}$ & $\begin{array}{l}\text { Simple design, } \\
\text { easy to } \\
\text { understand }\end{array}$ \\
\hline
\end{tabular}

The results of the analysis show that some elements should be combined and analyzed before use in the rehabilitation game. The elements of the game that were chosen were a story, objective, activity, marks, feedback, challenge, social interaction, competition or collaboration, level, and audio and visual elements. Interviews were conducted to assess whether all the elements chosen were appropriate for inclusion in the rehabilitation game. The feedback interviews were recorded and evaluated based on the percentage of respondents who agreed or disagreed. Only a majority percentage of votes received as confirmation.

\section{B. Technological Constraints}

Games for recovery post-stroke patients are very different from those for other users, due to the limited movement of 
these players. The literature review shows that post-stroke patients have technological, cognitive and physical constraints. These constraints must be defined so that the principles of interface design can be identified; otherwise, the game will not meet the requirements and post-stroke patients will face problems in terms of the movement exercises.

1) Physical Constraints: The physical constraints of post-stroke patients in terms of technology vary according to their level of ability. Post-stroke patients may experience physical changes such as slower response time, problems with balance and movement, weak limbs, problems with unbalanced posture and visual problems.

2) Cognitive Constraints: Cognitive function is decreased and the patient experiences changes in thinking. These factors include memory problems that lead to communication difficulties. Many post-stroke patients experience cognitive problems, and cognitive constraints are the most important factor to consider when designing the interface of rehabilitation games.

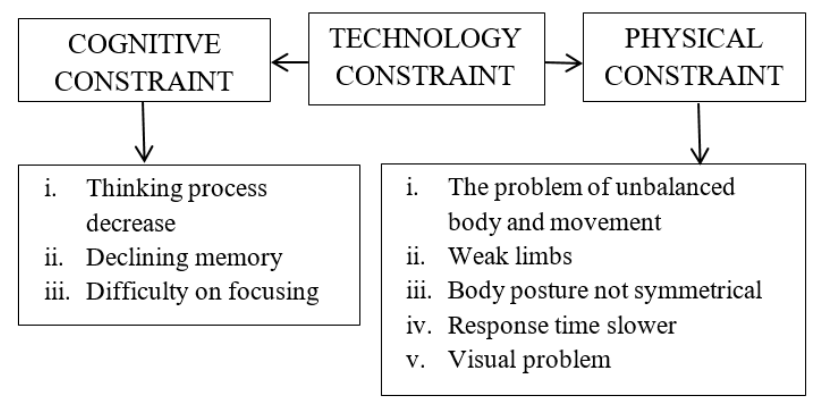

Fig. 1 Technological constraints

The technological constraints of post-stroke patients were identified and assessed using structured interviews with respondents. The feedback from the interviews was recorded and evaluated based on the percentage of respondents who agreed or disagreed. Only a majority percentage of votes received as confirmation.

\section{RESULT AND DISCUSSION}

\section{A. Type of Movement}

Movement exercises are a focus here since the main objective of this game is that post-stroke patients should carry out additional movement exercises at home. Many types of training are available, but this rehabilitation game focuses only on the training of the arm. From the research literature, the types of hand movement exercises that have been chosen are as follows:

1) Lifting the shoulder: This exercise requires the patient to sit on a chair with hands by his/her side. Patients are required to lift the shoulder to the ear.

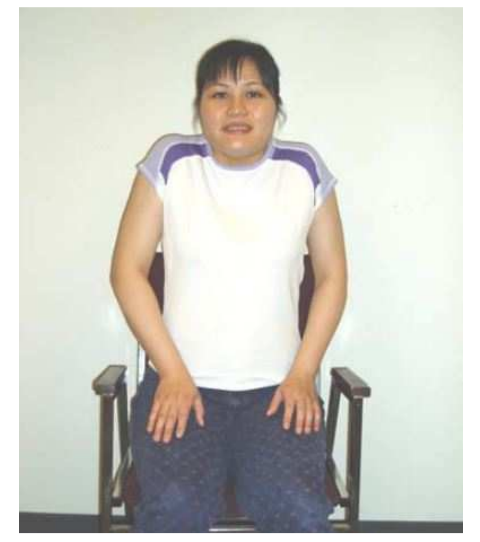

Fig. 2 Raising the shoulder

2) The Twist: This exercise requires the patient to sit on a chair, making sure the back is straight throughout the exercise. Both hands are held and pushed forward until a stretch is felt in the back. At the same time, the patient's body is turned to the left and right.
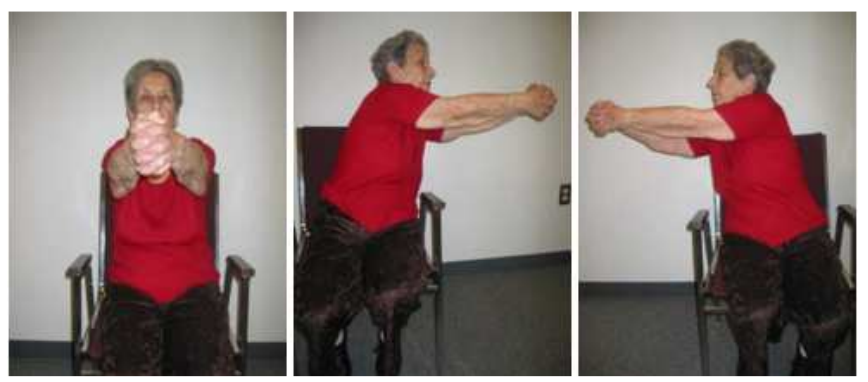

Fig. 3 The twist exercise

3) Arm Lift to the Side: This exercise requires the patient to sit on a chair, making sure the back is straight throughout this exercise. The arm is lifted to the side as high as possible, without exceeding shoulder height.

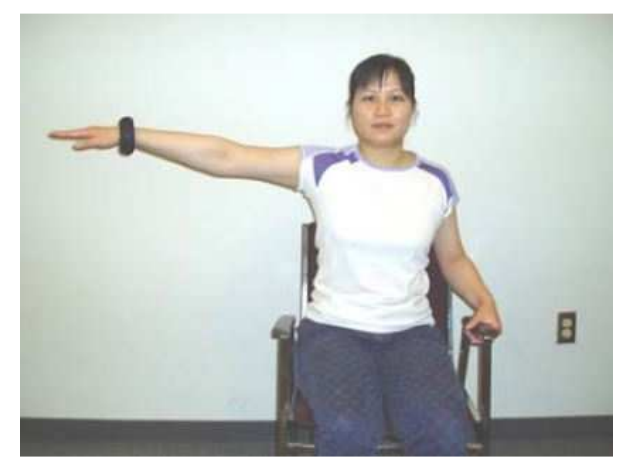

Fig. 4 Arm lift to the side

There are many advantages of doing these exercises. Researchers have found that if patients do this exercise for an additional 20 hours, patients will experience the following advantages [12]:

- Strengthening weak hands

- Improving weak hand movements

- Improving the ability to use the weak arm to perform daily activities

- Reduction in pain in the weak hand 


\section{- Improving life satisfaction}

The table below shows these movement exercises converted to game activities.

TABLE II

REHABILITATION GAME

\begin{tabular}{|c|l|l|l|}
\hline No & Type of movement & $\begin{array}{c}\text { Rehabilitation } \\
\text { game }\end{array}$ & \multicolumn{1}{c|}{ Remark } \\
\hline 1 & $\begin{array}{l}\text { Twist combined } \\
\text { with shoulder lift } \\
\text { catcher }\end{array}$ & $\begin{array}{l}\text { Butterfly } \\
\text { catch a butterfly using } \\
\text { the twist movement, } \\
\text { and needs to avoid the } \\
\text { obstacle using the } \\
\text { shoulder lift }\end{array}$ \\
\hline 1 & Arm lift to the side & Ping pong & $\begin{array}{l}\text { The player needs to } \\
\text { move the controller } \\
\text { by doing arm lift side } \\
\text { movement }\end{array}$ \\
\hline
\end{tabular}

\section{B. Principle of Interface Design}

The technology constraints of post-stroke patients identified by respondents were assessed using structured interviews. The feedback from the interviews was recorded and evaluated based on the percentage of respondents who agreed or disagreed, in the form of a percentage as shown in the table below.

TABLE III

FEEDBACK FROM TECHNOLOGY CONSTRAINTS INTERVIEWS

\begin{tabular}{|c|c|c|c|}
\hline Constraint & Problem & $\begin{array}{c}\text { Agree } \\
(\%)\end{array}$ & $\begin{array}{c}\text { Disagree } \\
(\%)\end{array}$ \\
\hline Cognitive & $\begin{array}{ll}\text { i. } & \text { Reduction in thinking } \\
& \text { process } \\
\text { ii. } & \text { Declining memory } \\
\text { iii. } & \text { Difficulty in focusing }\end{array}$ & $\begin{array}{l}100 \\
100 \\
100\end{array}$ & $\begin{array}{l}0 \\
0 \\
0\end{array}$ \\
\hline Physical & 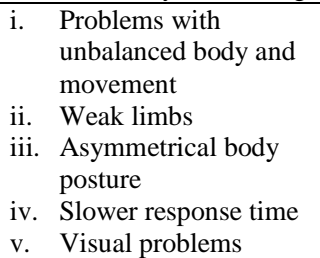 & $\begin{array}{l}100 \\
100 \\
100 \\
\\
100 \\
100\end{array}$ & $\begin{array}{l}0 \\
0 \\
0 \\
0 \\
0\end{array}$ \\
\hline
\end{tabular}

Based on the results, all respondents agreed $100 \%$ with the technology constraints of post-stroke patients. This enables the process to identify the principles of interface design needed to make the rehabilitation game easier.

In order to constantly motivate the player of the game, five basic principles of design are required, which were identified through an analysis of games designed for entertainment [13]. These are a story, ease of use, interactive feedback, encouraging exploration and a feeling of success. However, since the respondents did not agree with the story elements in this game, four basic principles can be applied in this rehabilitation game.

1) Ease of use: The interface allows players to communicate and explore the game, and its design must be easy to understand. The focus of the player is to reach the goal of the game rather than to learn to understand the interface design. The elements highlighted in this game are color, size and icon.

2) Interactive feedback: The game should be designed to provide effective feedback so that players can recognize and identify any errors made or successes achieved. Based on this feedback, players can improve their actions, and this can help players obtain a better understanding of the game. There are several types of feedback; in this game, visual and audio feedback are used.

3) Encouraging exploration: Games need to motivate players to explore and understand the capabilities of the game. In this way, players will become more proficient at controlling the characters in the game and avoiding various obstacles, and will become more familiar with the game. Indirectly, post-stroke patients will be doing repeated rehabilitation exercises.

4) Feeling of success: Players should be rewarded in order to motivate players to play continuously and master the game. These rewards act as an incentive to the player encourage them to play the game again after successfully achieving the goal, in order to get more rewards.

\section{Games Element}

The elements of the rehabilitation game were identified and assessed by respondents as being suitable for post-stroke patients. Respondents were given a description of the purpose of the interview. They were then asked to give feedback on whether or not the elements were appropriate for use in a rehabilitation game. Feedback from the interviews was recorded in the form of a percentage, as shown in the table below.

TABLE IV

FEEDBACK From GAME ELEMENTS INTERVIEWS

\begin{tabular}{|c|l|c|c|}
\hline No & \multicolumn{1}{|c|}{ Game Element } & Agree(\%) & Disagree(\%) \\
\hline 1 & Story & 40 & 60 \\
\hline 2 & Objective & 100 & 0 \\
\hline 3 & Activity & 100 & 0 \\
\hline 4 & Marks & 100 & 0 \\
\hline 5 & Feedback & 100 & 0 \\
\hline 6 & Challenge & 80 & 20 \\
\hline 7 & Social interaction: & 50 & 50 \\
& Competition & 50 & 50 \\
\hline 8 & Collaboration & 100 & 0 \\
\hline 9 & Level & 100 & 0 \\
\hline
\end{tabular}

The results of these interviews show that all the elements of the recovery game obtained agreement from the majority of respondents, except the elements of competition and cooperation which scored the same percentage, and the element of the story which scored only $20 \%$. Respondents did not like the story element, asthe time constraint, and were more interested in mini-games. Since the elements of competition and cooperation elements scored the same percentage, the post-stroke rehabilitation game will provide players with a choice to play in a competitive or collaborative setting. Figure 2 shows the elements of the rehabilitation game as confirmed by the respondents. 


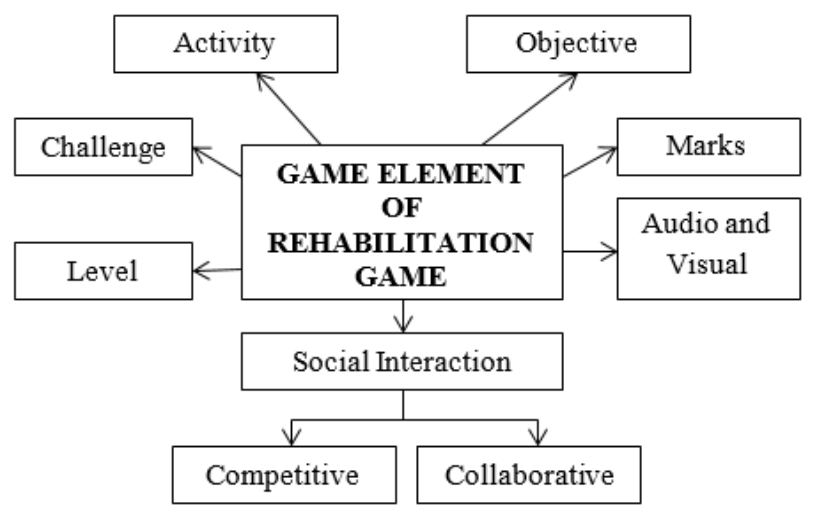

Fig. 5 Elements of the rehabilitation game

1) Objective: The objective of the rehabilitation game is to increase the motivation of the post-stroke patients so that they always strive to achieve the goals set for them. Indirectly, these patients carry out many movements when their focus is on achieving the goal of the game. Goal setting should be commensurate with the ability of post-stroke patients.

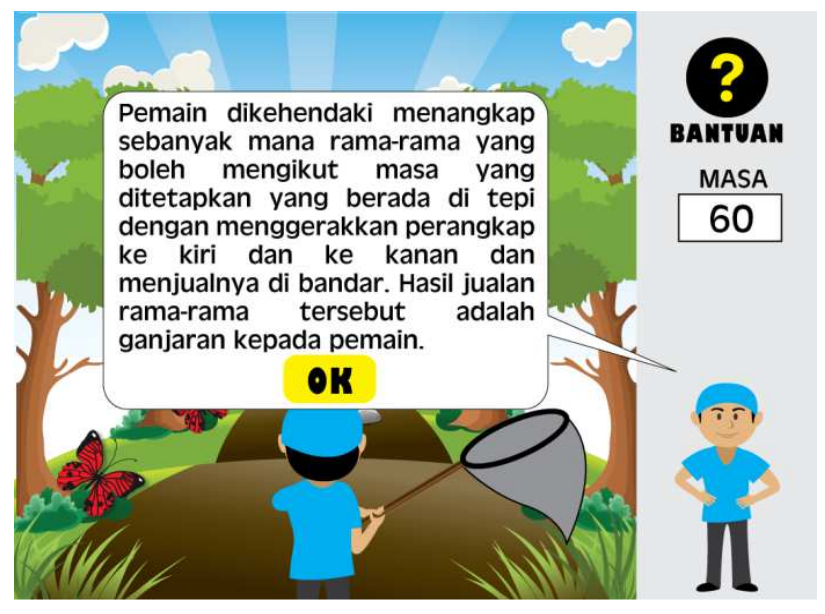

Fig. 6 Objective of the game

2) Activity: The activity element of the games involves movement of certain parts of the body, and should be compatible with rehabilitation exercises that patients do with a therapist. This element should also be easy for the player to apply in daily life. Activities should be more interesting and relate to the environment, and players should experience the game as a source of motivation to recover. If players feel good, the rehabilitation game has more impact meaning they become more active.

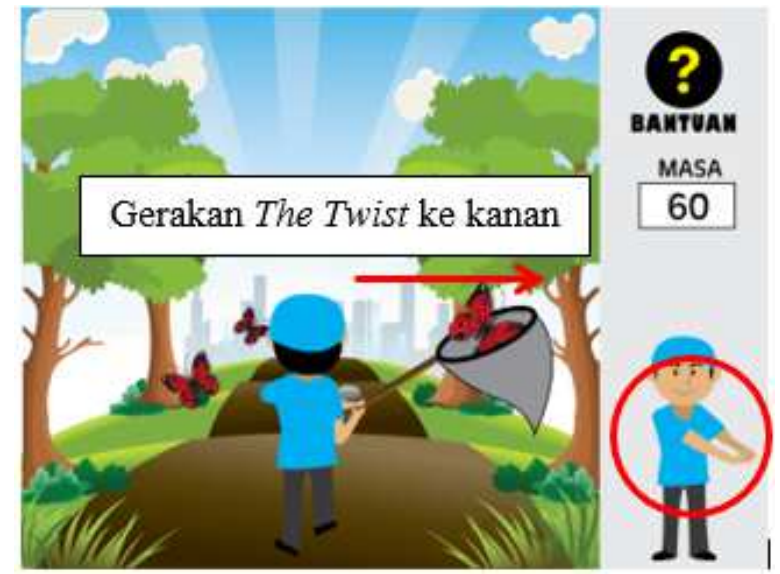

Fig. 7 Activity of the game

3) Marks: The marks element is a tool for measuring the progress and performance of the players in the rehabilitation game. This element gives feedback on the progress of post-stroke patients in the rehabilitation game. This element can also improve the motivation of post-stroke patients to keep playing, tempting them to become more successful by achieving a higher score.

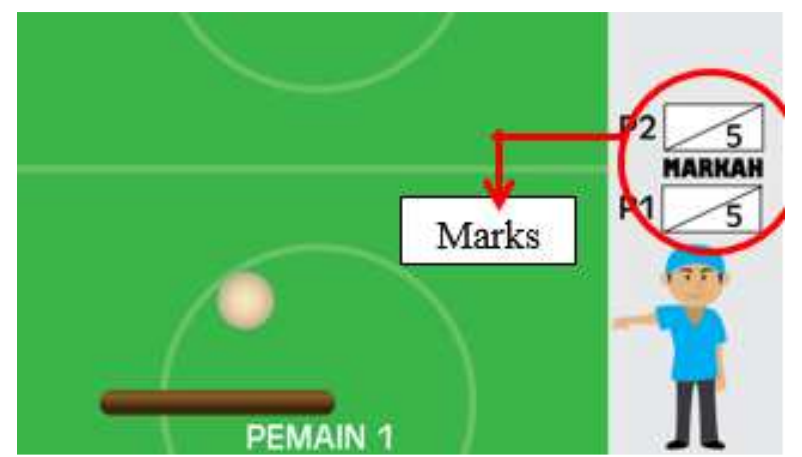

Fig. 8 Marks element of the game

4) Feedback: Feedback allows players to determine their progress and the impact of the action taken. There are two types of feedback: positive and negative. Feedback helps a player to become more active in the recovery process and assists players in improving movements.

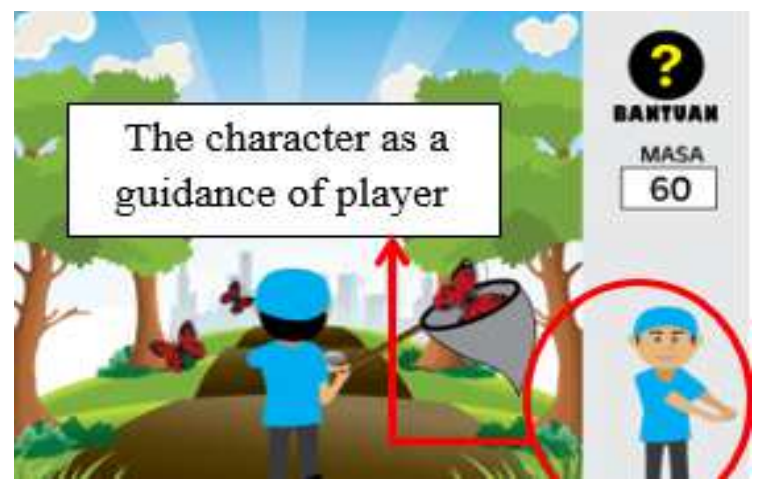

Fig. 9 Feedback in the game 
5) Challenge: The element of challenge should not be overlooked in the recovery game, since this is one of the objectives of the development of the game. The challenges that are appropriate for the post-stroke patients are slightly tough since they have difficulty in making large movements. The recovery process is achieved if they successfully complete the challenge of the game. This element can be motivational when players feel challenged both by the system and by other players; completing the challenge provides satisfaction to the player.

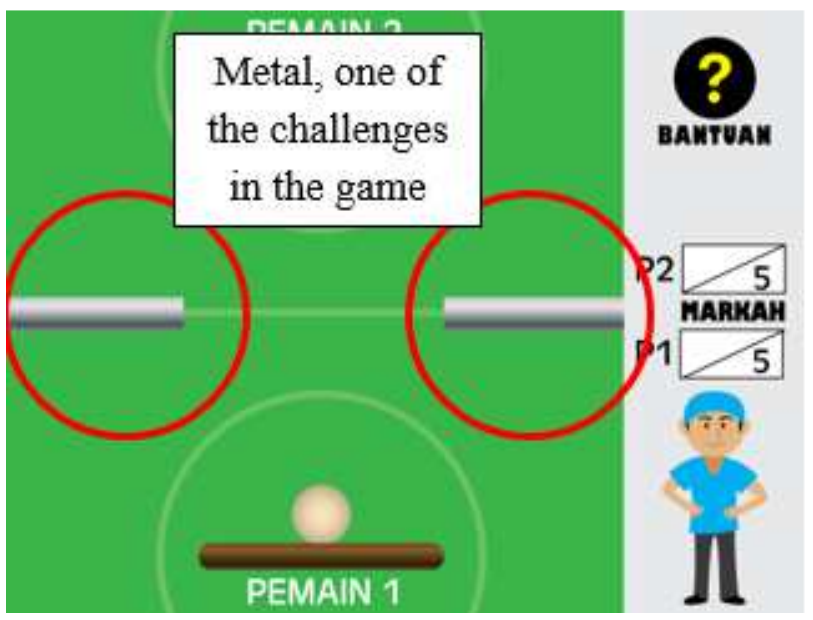

Fig. 10A challenge in the game

6) Social interaction: Social interaction forms a bridge between players to enable socializing with friends and family members. This element creates opportunities for poststroke patients to play continuously, since it reduces loneliness and allows a friend to play the game. Indirectly, post-stroke patients will carry out any repetitive motion exercises without being aware of it. This also can eliminate a lack of confidence, and patients will enjoy playing the game.

a. Competition: This element is another way to motivate players to play the game continuously, and is suitable for individuals who like to compete with an opponent. Players have two objectives: a focus on the goal of the game, and beating an opponent.
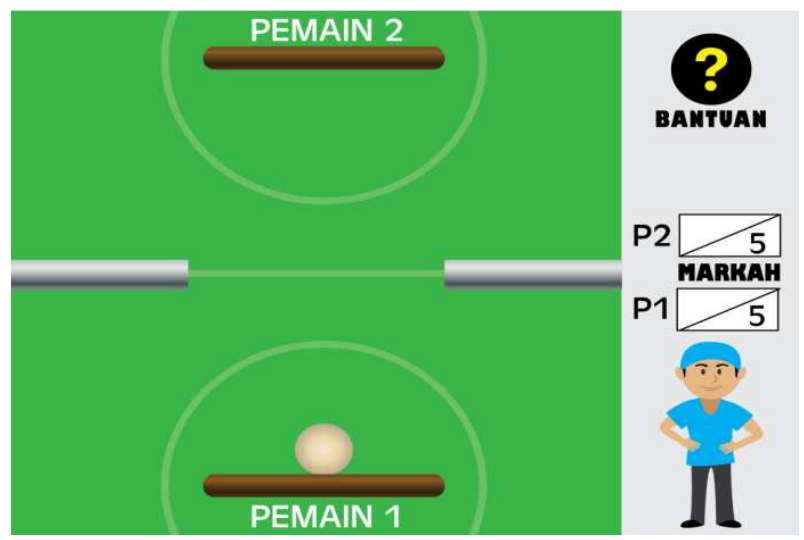

Fig. 11 Competitive element of the game

b. Collaboration: This is an element that makes the rehabilitation game more sociable, and is suitable for players who enjoy a more relaxed game; over time, it can build a relationship between players.

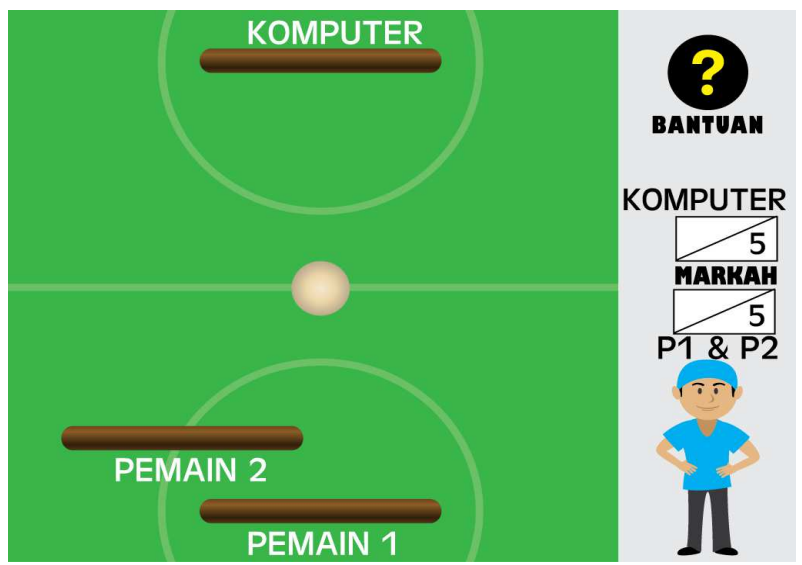

Fig. 12 Collaborative element of the game

7) Level: The level of difficulty of the rehabilitation game should be suitable for the ability of post-stroke patients, since their movements are limited. The higher the level difficulty achieved by post-stroke patients, the more progress made in their movement training. There are three levels of difficulty in the rehabilitation game: easy, medium and hard.

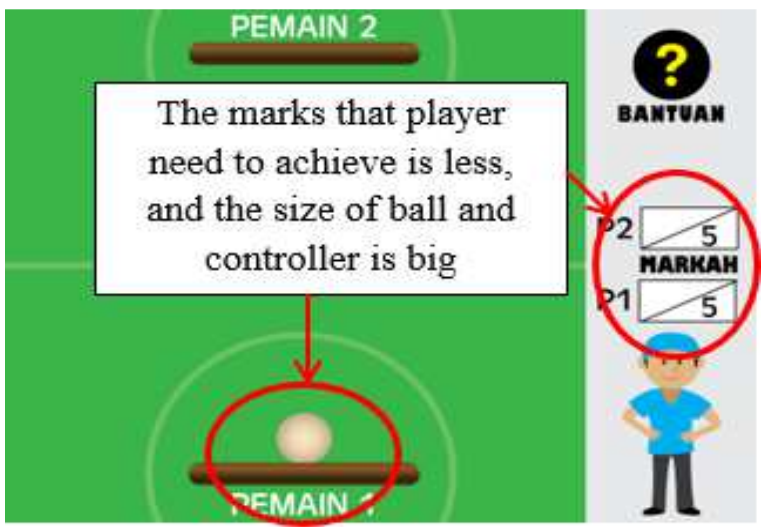

Fig. 13 Easy level

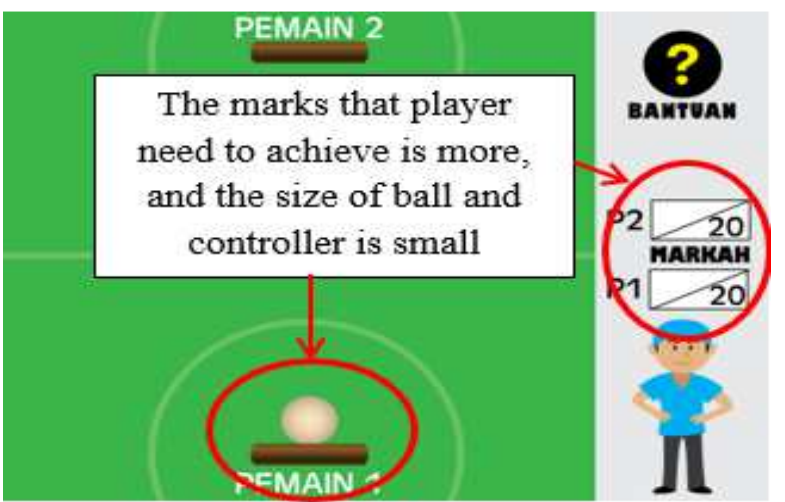

Fig. 14 Hard level

8) Audio and visual elements: Sound and graphics are important in any type of game, including for rehabilitation. This is an interesting element for players, and can keep the 
focus on playing and create an immersive feel for the player. An interesting and clear display also makes the player feel more comfortable, and creates enjoyment when playing the rehabilitation game.

\section{Prototype Testing}

The objective of prototype testing is to ensure the effectiveness of the rehabilitation game. The test methods used evaluation through observation and interviews with the respondents to verify the game. A set of interview questions were used to obtain feedback from respondents about the prototype post-stroke rehabilitation game. The objective of the interview was explained to each respondent before commencing the interview.

TABLE V

FEEDBACK FROM RESPONDENTS ON THE PROTOTYPE

\begin{tabular}{|c|c|c|c|}
\hline No & Question & $\begin{array}{l}\text { Agree } \\
(\%)\end{array}$ & $\begin{array}{l}\text { Disagree } \\
(\%)\end{array}$ \\
\hline 1 & $\begin{array}{l}\text { Is the background color suitable for the } \\
\text { game? }\end{array}$ & 80 & 20 \\
\hline 2 & $\begin{array}{l}\text { Do the color and size of the words } \\
\text { make the text easy to read? }\end{array}$ & 100 & 0 \\
\hline 3 & $\begin{array}{l}\text { Do the design, color and size of the } \\
\text { icons make them easy to understand? }\end{array}$ & 100 & 0 \\
\hline 4 & $\begin{array}{l}\text { Is the theme color of the game suitable } \\
\text { for recovery? }\end{array}$ & 80 & 20 \\
\hline 5 & $\begin{array}{l}\text { Is the design arrangement of the game } \\
\text { suitable? }\end{array}$ & 100 & 0 \\
\hline 6 & Is the feedback of the game helpful? & 100 & 0 \\
\hline 7 & $\begin{array}{l}\text { Are the instructions of the game } \\
\text { helpful? }\end{array}$ & 100 & 0 \\
\hline 8 & $\begin{array}{l}\text { Do the respondents feel relaxed while } \\
\text { performing tasks in this game? }\end{array}$ & 100 & 0 \\
\hline 9 & $\begin{array}{l}\text { Do respondents enjoy playing this } \\
\text { game? }\end{array}$ & 100 & 0 \\
\hline 10 & Is this game easy to use? & 100 & 0 \\
\hline
\end{tabular}

Based on the evaluation using observation and interviews, the majority of respondents agreed with the elements of the game, interface design and the type of game and movements used in the recovery and suggested some improvements. Table VI below shows some suggestions for this rehabilitation game.

TABLE VI

SUGGESTIONS FOR THE REHABILITATION GAME

\begin{tabular}{|c|l|c|}
\hline No & \multicolumn{1}{|c|}{ Question } & \multicolumn{1}{|c|}{ Suggestion } \\
\hline 1 & $\begin{array}{l}\text { Is the background color suitable } \\
\text { for the game? }\end{array}$ & $\begin{array}{l}\text { Background color of the } \\
\text { game need to be white- } \\
\text { toned so that the player can } \\
\text { focus on the character and } \\
\text { the activity of the game }\end{array}$ \\
\hline 2 & $\begin{array}{l}\text { Do the color and size of the } \\
\text { words make the text easy to } \\
\text { read? }\end{array}$ & $\begin{array}{l}\text { None } \\
\text { the icons make them easy to } \\
\text { understand? }\end{array}$ \\
\hline 4 & $\begin{array}{l}\text { Is the theme color of the game } \\
\text { suitable for recovery? }\end{array}$ & Same as feedback for 1 \\
\hline 5 & $\begin{array}{l}\text { Is the design arrangement of the } \\
\text { game suitable? }\end{array}$ & \multicolumn{1}{|c|}{ None } \\
\hline 6 & $\begin{array}{l}\text { Is the feedback of the game } \\
\text { helpful? }\end{array}$ & $\begin{array}{l}\text { None } \\
\text { helpful? }\end{array}$ \\
\hline 7 & $\begin{array}{l}\text { Are the instructions of the game } \\
\text { none }\end{array}$ & \\
\hline
\end{tabular}

\begin{tabular}{|c|l|c|}
\hline 8 & $\begin{array}{l}\text { Do the respondents feel relaxed } \\
\text { while performing task in this } \\
\text { game? }\end{array}$ & None \\
\hline 9 & $\begin{array}{l}\text { Do respondents enjoy playing } \\
\text { this game? }\end{array}$ & None \\
\hline 10 & Is this game easy to use? & None \\
\hline
\end{tabular}

\section{CONCLUSION}

The prototype game was developed based on the four aspects of technology constraints, type of exercise movement, the principles of interface design and the game elements, and was tested by post-stroke patients and family members. These users also provided some suggestions for improvement. There are certain weaknesses of this research, which need to be addressed in future. Overall, this research has managed to achieve the objectives, based on the scope of the research, that were set at the early stages of research. Suggestions for further research to be conducted in the future include the following:

i. The addition of more rehabilitation movement exercises. In this rehabilitation game, only three types of movement are used for interaction. To enable the rehabilitation game to be used more broadly by post-stroke patients, future work need to add more types of movement, for example body and leg exercises.

ii. The use of three dimensional (3D) movement. In this rehabilitation game, a two-dimensional (2D) element is used as the interface design. The use of a $3 \mathrm{D}$ display will increase the interest and create more motivation to play the rehabilitation game.

\section{ACKNOWLEDGEMENT}

This research is funded by Dana Cabaran Perdana DCP2017-007/1.

\section{REFERENCES}

[1] Gazihan Alankus (2011). Motion-based video games for stroke rehabilitation with reduced compensatory motions. Department of Computer Science and Engineering (Washington University St. Louis)

[2] Shaughnessy, Resnick, \& Macko. (2006). Testing a model of poststroke exercise behaviour. Rehabilitation Nursing, 31(1), 15-21.

[3] Shapi i, A. Mat Zin, N.A., Elaklouk, A.(2015). A game system for cognitive rehabilitation. Biomed Research International , 1-7.

[4] Lloyd-Jones, D., Adams, R., Brown, T., Carnethon, M., Dai, S., De Simone, G., et al. (2010). Heart disease and stroke statistics, 2010 update:A report from the American Heart Association. Circulation, 121, 46-215.

[5] Monica, S. C., Sergi, B., Lukas, Z. Esther, D. O., \& Paul, F. M. J. (2006). A Virtual reality system for motor and cognitive neurorehabilitation. European Project Presenccia.

[6] Alana D. G., Thiago C., Lucas F., \& Veronica T. (2012). Poster: Improving motor rehabilitation process through a natural interaction based system using Kinect sensor. IEEE Symposium on $3 D$ User Interface, 145-146.

[7] Ahmed Mohammed Elaklouk, Nor Azan Mat Zin , Azrulhizam Shapii.(2015) Investigating therapists` intention to use serious games for acquired brain injury cognitive rehabilitation, Journal of King Saud University Computer and Information Sciences . 160-169.

[8] Hsu, H.J. (2011). The potential of Kinect as interactive educational

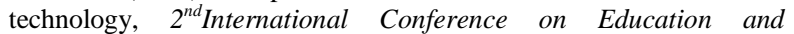
Management Technology, 13, 334-338.

[9] Aminian, M.R., Shapi i, A., Sulaiman, R. (2015). Writing in the Air Using Kinect and Growing Neural Gas Network , Jurnal Teknologi, 111-114.

[10] Aung, P., Tang, B., \& Mark, G. (2013). Understanding stroke patients' motivation for designing motivational rehabilitation games. 
Project of the School of Digital Media and Infocomm Technology, Singapore Polytechnic.

[11] Perry, J.C., et al. (2011). Effective game use in neurorehabilitation: User-centered perspectives. Handbook of Research on Improving Learning and Motivation through Educational Games, 683-725.

[12] Elaklouk, A, Mat Zin, N. Shapii.,(2013). A Conceptual Framework for Designing Brain Injury Cognitive Rehabilitation Gaming System, International,Journal of Digital Content Technology and its Applications, 7(15):31-41

[13] Chang, Y.-J., Chen, S.-F.,Huang, J.-D. (2011). A Kinect-based system for physical rehabilitation: A pilot study for young adults with motor disabilities. Research in Development Disabilities, 32, 2566-2570.

[14] Alex, R., Jonathan, E., Thomas, P., \& John, F. 2012. Accessorized Therapeutic Game Experiences for Tablets. Grand Valley State University.

[15] Shapii, A., Ghulam, S. (2016). Model for Educational Game using Natural User Interface, International Journal of Computer Games Technology, 1-7.

[16] Freitas, D.Q., Da Gama, A.E.F., Figueiredo, L., Chaves, T.M. Marques-Oliveira, D., Teichrieb, V., \& Araujo, C. (2012). Development and evaluation of a Kinect based motor rehabilitation game. Proceedings of SB Games, 144-153.
[17] Eng, J., \& Harris, J. (2009). Graded Repetitive Arm Supplementary Program.Neurorehabilitation Research Program, University of British Columbia.

[18] Whitton, N. (2010). Game engagement theory and adult learning.Simulation \& Gaming, 1-15.

[19] Gazihan Alankus, Amanda Lazar, Matt May, Caitlin Kelleher. (2010). Towards Customizable Games for Stroke Rehabiltation. CHI 2010: Therapy and Rehabilitation: 2113-2122.

[20] Timmermans A. A., Seelen H. A., Willmann R. D., Kingma H. (2009). Technology-assisted training of arh-hand skills in stroke: Concept on reacquisition of motor control and therapist guidelines for rehabilitation technology design. Journal of neuroengineering. 1186-1191.

[21] Aung Pyae, Tang Boon, Mark Gossage. (2013). Understanding Stroke Patients' Motivation for Designing Motivational Rehabilitation Games. Project from School of Digital Media and Infocomm Technology, Singapore Polytechnic.

[22] Daniel Q. Freitas, Alana E. F., Da Gama, Lucas Figueiredo, Thiago M. Chaves, Déborah Marques-Oliveira, Veronica Teichrieb, Cristiano Araújo. (2012). Development and Evaluation of a Kinect Based Motor Rehabilitation Game. Proceedings of SBGames: 144153. 